\title{
Piezoelectric properties of PZT by an ethylene glycol-based chemical solution synthesis
}

\author{
Ewout van der Veer $^{1} \cdot$ Beatriz Noheda ${ }^{1}$ Mónica Acuautla $\mathbb{B}^{2}$
}

Received: 30 June 2021 / Accepted: 19 September 2021 / Published online: 29 October 2021

(c) The Author(s) 2021

\section{Abstract}

We have investigated a water-stable sol-gel method based on ethylene glycol as a solvent and bridging ligand for the synthesis of ferroelectric lead zirconate titanate in bulk and thin film forms. This method offers lower toxicity of the solvent, higher stability toward atmospheric moisture and a simplified synthetic procedure compared to traditional sol-gel methods. However, the piezoelectric properties of products produced using this method have yet to be systematically studied. We have measured the ferroelectric and piezoelectric properties and compared them to existing literature using different synthesis techniques. Ceramic pellets of Nb-doped lead zirconate titanate (PNZT) in the tetragonal phase were produced with high density and good piezoelectric properties, comparable to those reported in the literature and those found in commercial piezoelectric elements. In addition, a nine-layer thin film stack was fabricated by spin coating onto platinized silicon substrates. The films were crack-free and showed a perovskite grain structure with a weak (111) orientation. Piezoelectric measurements of the film showed a piezoelectric coefficient comparable to literature values and good stability toward fatigue.

\section{Graphical Abstract}

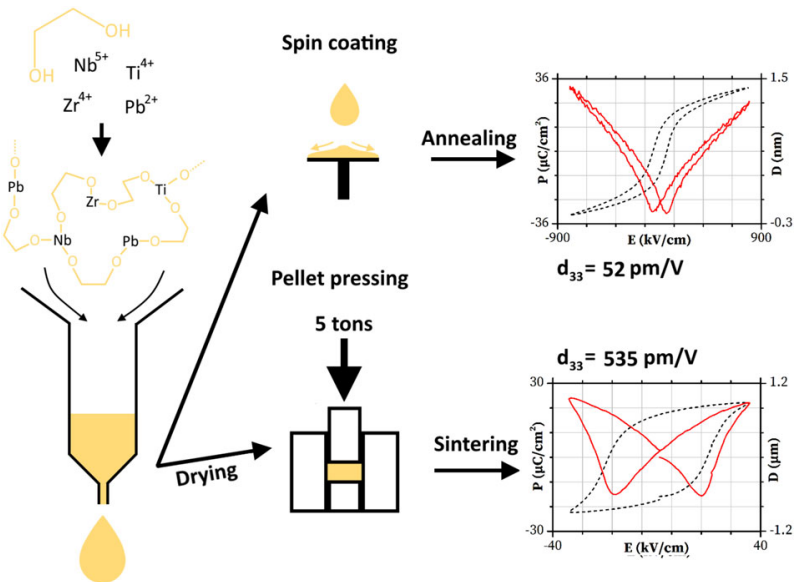

Keywords Ferroelectric $\cdot$ Sol-gel $\cdot$ PZT $\cdot$ Ethylene glycol $\cdot$ CSD

Mónica Acuautla

m.i.acuautla.meneses@rug.nl

1 Zernike Institute for Advanced Materials, Nijenborgh 4, 9747AG

Groningen, The Netherlands
2 Engineering and Technology Institute Groningen, Nijenborgh 4, 9747AG Groningen, The Netherlands 


\section{Highlights}

- Pellets and thin films of PZT were produced using an ethylene glycol-based CSD method.

- Ferroelectric and piezoelectric properties of these materials were measured and compared to literature.

- These properties rival literature values.

\section{Introduction}

Sol-gel methods are commonly used for the fabrication of oxide materials with a wide range of functionalities [1-5]. These methods involve the synthesis of a precursor solution (known as 'sol') containing oligomeric chains of metal ions and oxygen atoms. Treatment of the sol, for example by the addition of water or by heating, causes the formation of a continuous metal-oxygen network, leading to gelation of the sol. The sol may be processed into a variety of products, such as bulk powders (by simply heating the gel), thin films (by deposition of the sol onto a substrate, e.g. by spin coating) or a multitude of other forms [4, 6]. Employing a sol-gel-type synthesis for the production of oxide materials facilitates the control of composition and doping, making high homogeneity and short fabrication cycles possible [4]. Furthermore, when used to fabricate thin films, it can give rise to smooth films covering a large surface area with a wide range of film thicknesses up to several micrometers.

One material which has been produced using a sol-gel method is the well-known lead zirconate titanate solid solution $\left(\mathrm{PbZr}_{1-x} \mathrm{Ti}_{x} \mathrm{O}_{3}\right.$, also known as PZT) [7, 8], which is ferroelectric and, thus, piezoelectric, allowing for its use as sensors and actuators [9]. The PZT composition with $x=$ 0.48 lies at a phase boundary between two different crystal structures with tetragonal (for Ti-rich compositions) and rhombohedral (for Zr-rich compositions) symmetries, where monoclinic structures have been observed [10]. At this boundary, known as the morphotropic phase boundary (MPB), the piezoelectric coefficients are maximized [11]. The piezoelectric parameters of PZT can be further improved through chemical doping with elements such as niobium $\left(\mathrm{PbNb}_{\mathrm{y}}\left(\mathrm{Ti}_{x} \mathrm{Zr}_{1-x}\right)_{1-y} \mathrm{O}_{3}\right.$ or PNZT) $[12,13]$.

Traditional sol-gel methods used for the production of thin films of PZT, first reported in the seminal work by Budd et al. [7], make use of the highly toxic 2-methoxyethanol as a solvent and alkoxides and acetates as the precursors for lead, zirconium, and titanium. These methods rely on hydrolysis and condensation reactions of the alkoxide precursors to form a polymeric network of metal-oxygen-metal bonds. These methods use water for the initiation of the hydrolysis reaction. Hence, sols produced using such an approach tend to be sensitive to the presence of water [4]. As a result, these sols require storage and processing in an oxygen-free and waterfree environment, such as a glovebox.

A simplified sol-gel method was developed by $\mathrm{Yi}$ and Sayer [5], which is based on the use of acetic acid to chelate the metal ions. The resulting metal alkoxide acetates are dissolved in a water-based solution. This method does not require rigorous water-free storage or refluxing/distillation procedures, which is the case for the conventional sol-gel method. Nevertheless, the species present in the solution still depend on the concentration of water.

More recently, there has been an interest in the development of chemical solution deposition (CSD) methods that are not based on hydrolysis-condensation reactions, instead relying on different types of reactions. These include the well-known Pechini process [2, 4], which uses citric acid as a chelating agent and ethylene glycol as a bridging molecule between metal ions; nonaqueous sol-gel methods [14], in which metal-oxygen-metal bonds are formed without hydrolysis and condensation; and the citrate method [2,4]. A final example of such a CSD method is based on only ethylene glycol as a bridging ligand and common alkoxides and acetates as reagents. This method was reported to be nontoxic, more stable to atmospheric moisture, able to provide thicker single layers and offer a more straightforward synthesis procedure [2, 15]. However, the ferroelectric and piezoelectric properties of materials produced using this method have not been systematically compared to those using other synthesis methods. It is important for practical applications of this method to ascertain that the increased organic content of the sol does not degrade these properties.

We aim to fill this gap by measuring the piezoelectric and ferroelectric properties of bulk and thin film products of the ethylene glycol-based CSD method and comparing them to existing literature. We show that multilayer stacks of thin films can be produced without cracks or parasitic phases by controlling the deposition and heat treatment procedures. Thus, despite the presence of a large amount of organic material in the as-deposited film, which can reduce film quality, the piezoelectric behavior of the bulk and thin film products are comparable to reported values for films of similar characteristics.

\section{Materials and methods}

\subsection{Sol synthesis}

$7.5 \mathrm{~g}$ of freeze-dried lead acetate $\left(\mathrm{Pb}\left(\mathrm{CH}_{3} \mathrm{COO}\right)_{2}, \mathrm{PbAc}_{2}\right.$, $23 \mathrm{mmol}, 10 \mathrm{~mol} \%$ excess, $\geq 99 \%$, Sigma Aldrich) and $9.4 \mathrm{~mL}$ ethylene glycol $\left(\left(\mathrm{CH}_{2} \mathrm{OH}\right)_{2}, \mathrm{EG}\right)$ were added to a three-necked flask under a $0.5 \mathrm{~L} / \mathrm{min}$ argon flow. An excess of lead acetate 
was used to compensate for losses due to evaporation and diffusion during the heat treatment steps. The suspension was heated to $90^{\circ} \mathrm{C}$ while stirring to dissolve the solids, then to $110^{\circ} \mathrm{C}$ to expel any remaining water from the solution. The sol was subsequently cooled to $90^{\circ} \mathrm{C}$. $2.857 \mathrm{~mL}$ of titanium isopropoxide $\left(\mathrm{Ti}\left(\mathrm{OCH}\left(\mathrm{CH}_{3}\right)_{2}\right)_{4}, 2.743 \mathrm{~g}, 9.65 \mathrm{mmol}, 97 \%\right.$, Sigma Aldrich), $0.210 \mathrm{~mL}$ niobium ethoxide $\left(\mathrm{Nb}\left(\mathrm{OCH}_{2} \mathrm{CH}_{3}\right)_{5}\right.$, $0.266 \mathrm{~g}, 0.836 \mathrm{mmol}, 99.95 \%$, Sigma Aldrich) and $4.686 \mathrm{~mL}$ of a $70 \mathrm{wt} . \%$ solution of ziconium n-propoxide in 1-propanol $\left(\mathrm{Zr}\left(\mathrm{OCH}_{2} \mathrm{CH}_{2} \mathrm{CH}_{3}\right)_{4}, 3.425 \mathrm{~g} \mathrm{Zr}\left(\mathrm{OCH}_{2} \mathrm{CH}_{2} \mathrm{CH}_{3}\right)_{4}, 10.5 \mathrm{mmol}\right.$, Sigma Aldrich) were dissolved in $6.1 \mathrm{~mL}$ 1-propanol under inert atmosphere. The $\mathrm{Ti} / \mathrm{Nb} / \mathrm{Zr}$ solution was added to the lead sol slowly limiting exposure to air. Some precipitate formed upon addition. A further $15.7 \mathrm{~mL}$ of EG was added, yielding $30 \mathrm{~mL}$ of solution at a concentration of metal ions of $1.5 \mathrm{M}$ with a nominal composition of $\mathrm{Pb}_{1.1} \mathrm{Nb}_{0.04}\left(\mathrm{Zr}_{0.52} \mathrm{Ti}_{0.48}\right)_{0.96} \mathrm{O}_{3}$. The suspension was stirred at $90^{\circ} \mathrm{C}$ until all precipitate had redissolved. The sol was cooled to room temperature and 4 vol. $\%$ formamide $\left(\mathrm{HCONH}_{2}, \geq 99 \%\right.$, Sigma Aldrich) was added as a drying control chemical additive to limit the formation of cracks in the films [1]. A second sol was made in the same way, using a $0 \%$ excess of lead precursor. This sol was used for the preparation of bulk PNZT (see below).

A separate lead oxide $(\mathrm{PbO})$ sol was fabricated by dissolving $9.76 \mathrm{~g}$ of freeze-dried lead acetate $\left(\mathrm{Pb}\left(\mathrm{CH}_{3} \mathrm{COO}\right)_{2}\right.$, $\mathrm{PbAc}_{2}, 23 \mathrm{mmol}, 10 \mathrm{~mol} \%$ excess, $\geq 99 \%$, Sigma Aldrich) in $30 \mathrm{~mL}$ of ethylene glycol $\left(\left(\mathrm{CH}_{2} \mathrm{OH}\right)_{2}, \mathrm{EG}\right)$ while stirring to a final concentration of $1 \mathrm{M}$.

\subsection{Substrate preparation}

The substrates used for deposition of the PNZT sol were prepared from a (001) oriented silicon wafer without thermal oxide (Ted Pella) diced into $1 \times 1 \mathrm{~cm}$ squares. The silicon substrates were cleaned ultrasonically in acetone, demineralized water and ethanol for $10 \mathrm{~min}$ each. The substrates were subsequently blow-dried using compressed air and loaded into a Kurt J. Lesker sputtering system. The substrates were $\mathrm{O}_{2}$ plasma cleaned $(0.15 \mathrm{mbar}, 200 \mathrm{~W}$, $5 \mathrm{~min}$ ) after which a titanium adhesion layer of $5 \mathrm{~nm}$ was DC sputtered $(200 \mathrm{~W}, 0.2 \mathrm{~nm} / \mathrm{s})$ without breaking the vacuum. Subsequently, a 100 -nm-thick electrode of platinum was DC sputtered $(200 \mathrm{~W}, 1.61 \mathrm{~nm} / \mathrm{s})$ onto the adhesion layer. The full electrode stack was annealed in a box furnace in air $\left(450{ }^{\circ} \mathrm{C}, 90 \mathrm{~min}\right.$, ramp rate $\left.14.2{ }^{\circ} \mathrm{C} / \mathrm{s}\right)$.

\subsection{Deposition procedure and heat treatment}

The platinized silicon substrates prepared as described above were again cleaned ultrasonically in acetone, demineralized water, and ethanol for $10 \mathrm{~min}$ each. The substrates were blow dried using compressed air and $\mathrm{UV} / \mathrm{O}_{3}$ treated in an Ossila UV ozone cleaner for $10 \mathrm{~min}$ to remove any residual organic contamination from the surface. The substrates were immediately placed in the center of the vacuum chuck of a spin coater. Seventy-five microliters of the $1.5 \mathrm{M}$ sol was deposited onto the substrates. The spin coater was subsequently ramped up to the desired speed at $1000 \mathrm{rpm} / \mathrm{s}$. It was held at this speed for $30 \mathrm{~s}$, then slowed to a stop at $1000 \mathrm{rpm} / \mathrm{s}$. The film was then placed on a hotplate at $230{ }^{\circ} \mathrm{C}$ for drying. Additional layers were deposited after drying for the production of multilayer films. After the deposition of up to three layers, the films were pyrolyzed at $380^{\circ} \mathrm{C}$ on the hotplate and annealed by placing them in a preheated box furnace at $650{ }^{\circ} \mathrm{C}$ for $10 \mathrm{~min}$. Multilayer stacks of up to nine single deposited layers were produced, for which pyrolysis and annealing steps were performed every third layer. Multiple annealed layers are required to prevent the formation of leakage paths through the film. A $4 \times 4$ grid of circular top electrodes of $100 \mathrm{~nm}$ of platinum was sputter deposited onto the films using a hard mask.

\subsection{Pellet preparation}

For the preparation of bulk pellets of PNZT, the sol without an excess of lead was stirred and heated at $230{ }^{\circ} \mathrm{C}$ on a hotplate. Some of the resulting gel was used for thermogravimetric analysis (TGA) and differential thermal analysis (DTA). The remaining gel was heated in a box furnace to $450{ }^{\circ} \mathrm{C}$ for $1 \mathrm{~h}$ to remove the organic groups. The resulting powder was ball milled for $30 \mathrm{~min}$ and heated again to $450{ }^{\circ} \mathrm{C}$ for $10 \mathrm{~min}$. The PNZT powder was pressed into $0.48 \mathrm{~g}$ pellets with a nominal diameter of $10 \mathrm{~mm}$ under a load of $6.4 \mathrm{ton} / \mathrm{cm}^{2}$ using poly(vinyl alcohol) as a binder. The green body had a density of $5292 \mathrm{~kg} / \mathrm{m}^{3}$. The pellets were placed on top of a piece of platinum inside an alumina crucible with a mixture of lead zirconate and $10 \%$ zirconium dioxide to control the composition of the atmosphere during sintering (Fig. 1) [16]. They were sintered in a box furnace at $1250^{\circ} \mathrm{C}$ for $2 \mathrm{~h}$.

\subsection{Characterization}

Grain structures of the films and pellets and film thicknesses were studied using an FEI Nova NanoSEM 650 scanning electron microscope. Grinding and polishing of the pellet before Scanning electron microscopy (SEM) analysis was done using diamond suspension down to $1 \mu \mathrm{m}$ (Struers company) and colloidal silica suspension down to $40 \mathrm{~nm}$ (Struers OP-U). The pellet was then lightly etched in $100 \mathrm{~mL}$ of $15 \%$ hydrochloric acid with a drop of hydrofluoric acid for $30 \mathrm{~s}$. X-ray diffraction data were collected using a PanAnalytical X'Pert Pro MRD or a Bruker D8 Advance diffractometer (both in Bragg-Brentano geometry) for the films and pellets, respectively. DTA-TGA data was collected in argon from 


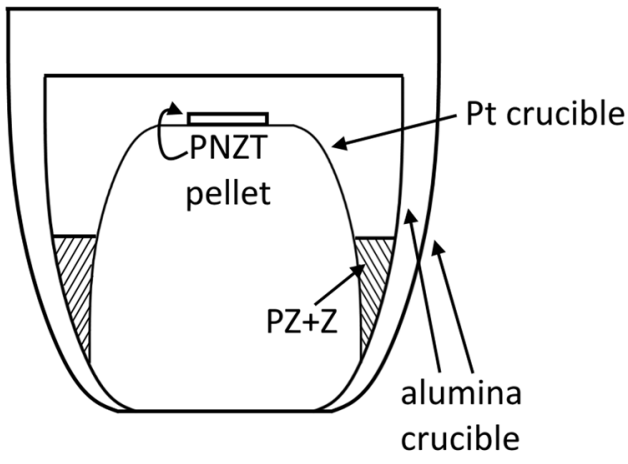

Fig. 1 Crucible setup used for sintering the PNZT pellet. $\mathrm{PZ}+\mathrm{Z}$ : $\mathrm{PbZrO}_{3}+10 \% \mathrm{ZrO}_{2}$

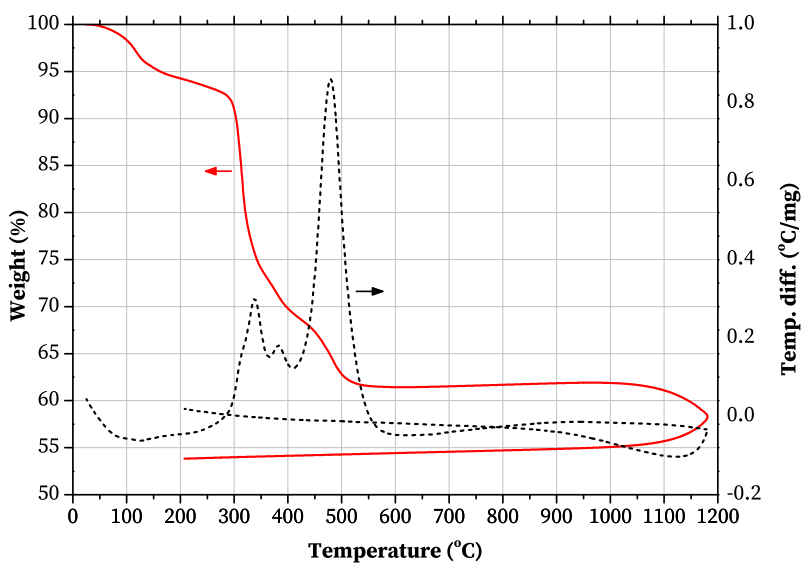

Fig. 2 DTA and TGA traces of the sol dried at $230^{\circ} \mathrm{C}$

$30{ }^{\circ} \mathrm{C}$ to $1200{ }^{\circ} \mathrm{C}$ at a heating rate of $10^{\circ} \mathrm{C} / \mathrm{min}$ using a TA instruments SDT 2960 differential scanning calorimeter. Finally, ferroelectric and piezoelectric properties of the films and pellets were measured using a state-ofthe-art AixACCT TF analyzer 2000 ferroelectricpiezoelectric characterization system with an AixACCT double beam (films) or a Sios single beam (pellets) interferometer. The use of a double-beam interferometer eliminates the contribution of the bending of the substrate to the measured deformation of the film.

\section{Results and discussion}

Properties of the sol, as well as structural, ferroelectric, and piezoelectric properties of the PNZT films and bulk ceramic pellets have been investigated.

Figure 2 contains plots of the DTA and TGA data collected from the sol dried at $230{ }^{\circ} \mathrm{C}$ on a hotplate. Initial weight loss occurs around $100^{\circ} \mathrm{C}$ and is likely associated with loss of a small amount of water from the air adhering to the sample, crucible or the inside of the DTA-TGA apparatus. This residual water cannot originate from the sample itself as it was heated to $230{ }^{\circ} \mathrm{C}$ prior to the measurement. Further

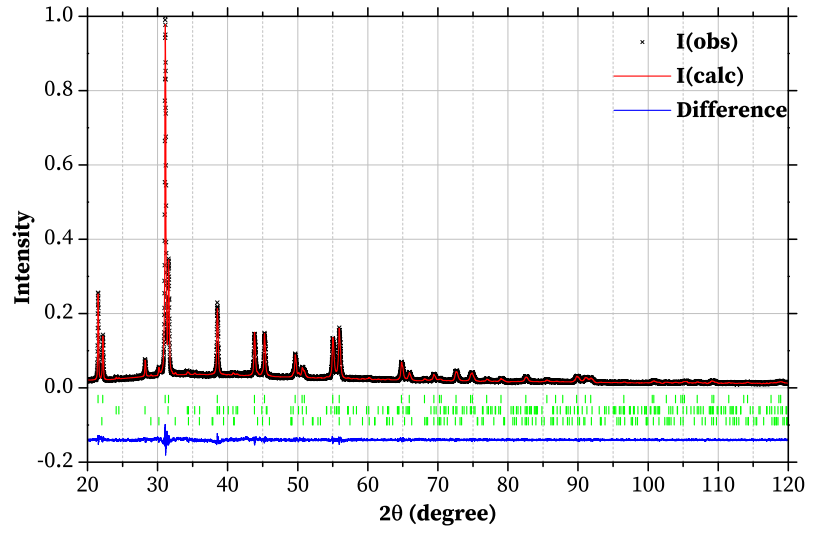

Fig. 3 X-ray diffraction pattern of the pellet and a fit of the profile. The green indicators show the expected peak positions of (from top to bottom) a rhombohedral PNZT phase, a monoclinic $\mathrm{ZrO}_{2}$ phase, and a $\beta-\mathrm{PbO}$ phase, respectively

decomposition of the sample takes place in three steps at 320 , 380 , and $470{ }^{\circ} \mathrm{C}$. Weight loss above $1000^{\circ} \mathrm{C}$ is due to evaporation of lead from the sample. These results closely resemble those found in previous reports on diol-based sol-gel methods [17, 18]. A total weight loss of approximately $38 \%$ was observed up to $600^{\circ} \mathrm{C}$.

We found that this type of sol is much less sensitive to the presence of water (for example, from the atmosphere), than traditional sols based on 2-methoxyethanol. These are generally used in an inert atmosphere to prevent undesired gelation. On the contrary, no gelation occurred in the ethylene glycol-based sol for at least a month even after the direct addition of $10 \%$ of water to the sol. This opens up possibilities for using the sol in air.

\subsection{Bulk}

PNZT pellets were produced from the PNZT sol with a $0 \%$ excess of lead precursor. The sol was dried at $230{ }^{\circ} \mathrm{C}$ and pyrolyzed at $450{ }^{\circ} \mathrm{C}$. Pellets with a nominal diameter of $10 \mathrm{~mm}$ were pressed from this powder at 6.4 ton $/ \mathrm{cm}^{2}$ and sintered at $1250^{\circ} \mathrm{C}$ for $2 \mathrm{~h}$. After sintering, the pellet had a diameter of $8.52 \mathrm{~mm}$, a thickness of $0.69 \mathrm{~mm}$ and a density of $8129 \mathrm{~kg} / \mathrm{m}^{3}, 99.3 \%$ of the calculated maximum density of $8188 \mathrm{~kg} / \mathrm{m}^{3}$.

Figure 3 shows an $\mathrm{X}$-ray diffraction pattern of the pellet after sintering at $1250{ }^{\circ} \mathrm{C}$. A LeBail fit of this pattern was made using a combination of a tetragonal PNZT phase (space group $\mathrm{P} 4 \mathrm{~mm})$, a monoclinic zirconia phase $\left(\mathrm{P} 2_{1} / \mathrm{c}\right)$, and an orthorhombic $\beta$ - $\mathrm{PbO}$ phase $(\mathrm{Pbcm})$. The latter two phases are minor impurities. Blown-up versions of the (100), (110), and (111) peaks of the pattern are shown in Fig. 4. The nominal composition of the material is at the MPB between the rhombohedral and tetragonal phases, which is known to have the best piezoelectric properties 
Fig. 4 Blow-ups of the a (100), b (110), and c (111) peaks of the pattern in Fig. 3

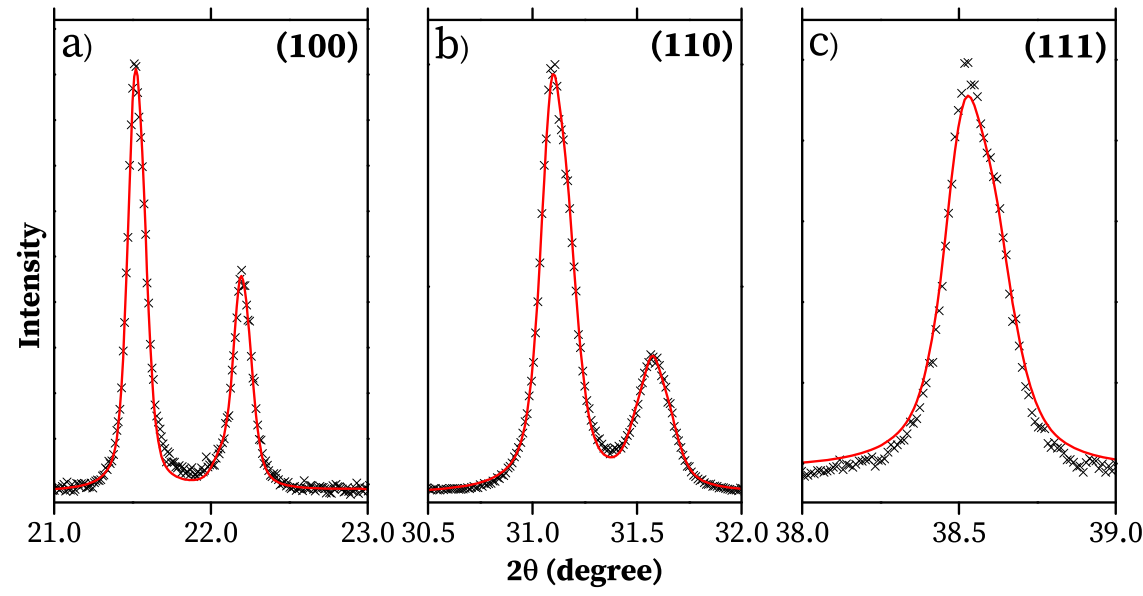

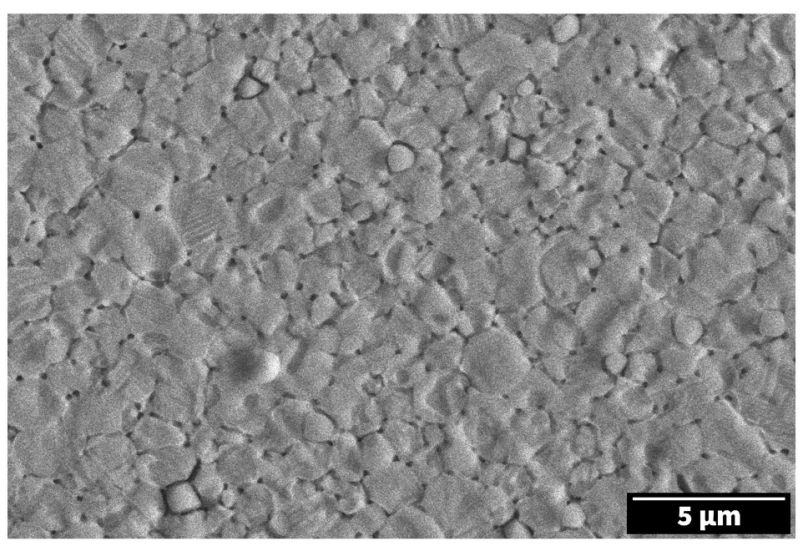

Fig. 5 Scanning electron microscopy image of a pellet sintered at $1250{ }^{\circ} \mathrm{C}$ showing PNZT grains as well as ferroelectric-ferroelastic domains on some of the grains

$[10,11,19,20]$. However, XRD analysis shows that the material is in fact in the titanium-rich tetragonal phase, due to the formation of a minor zircona impurity. The process by which this zirconia phase is formed is presently unknown. The formation of this phase as well as its effects on the properties of our products are the topic of ongoing investigation in our group.

SEM of the pellet (Fig. 5) shows a dense grain structure, with visible ferroelastic domains on some of the grains. The diameters of 35 grains were measured, yielding an average grain size of $1.21 \mu \mathrm{m}$ with a standard deviation of $0.54 \mu \mathrm{m}$. The impurity phases observed in the X-ray diffraction pattern are not clearly visible in the micrograph.

The pellet was poled in a silicone oil bath at $100^{\circ} \mathrm{C}$ with an electric field of $29 \mathrm{kV} / \mathrm{cm}$ for $30 \mathrm{~min}$ to align the dipoles in the material. Ferroelectric property measurements of the bulk ceramic pellet were performed with a frequency of $10 \mathrm{~Hz}$, yielding the polarization-electric field hysteresis loops and strain-electric field ("butterfly") loops expected for a ferroelectric, as displayed in Fig. 6a. The remnant
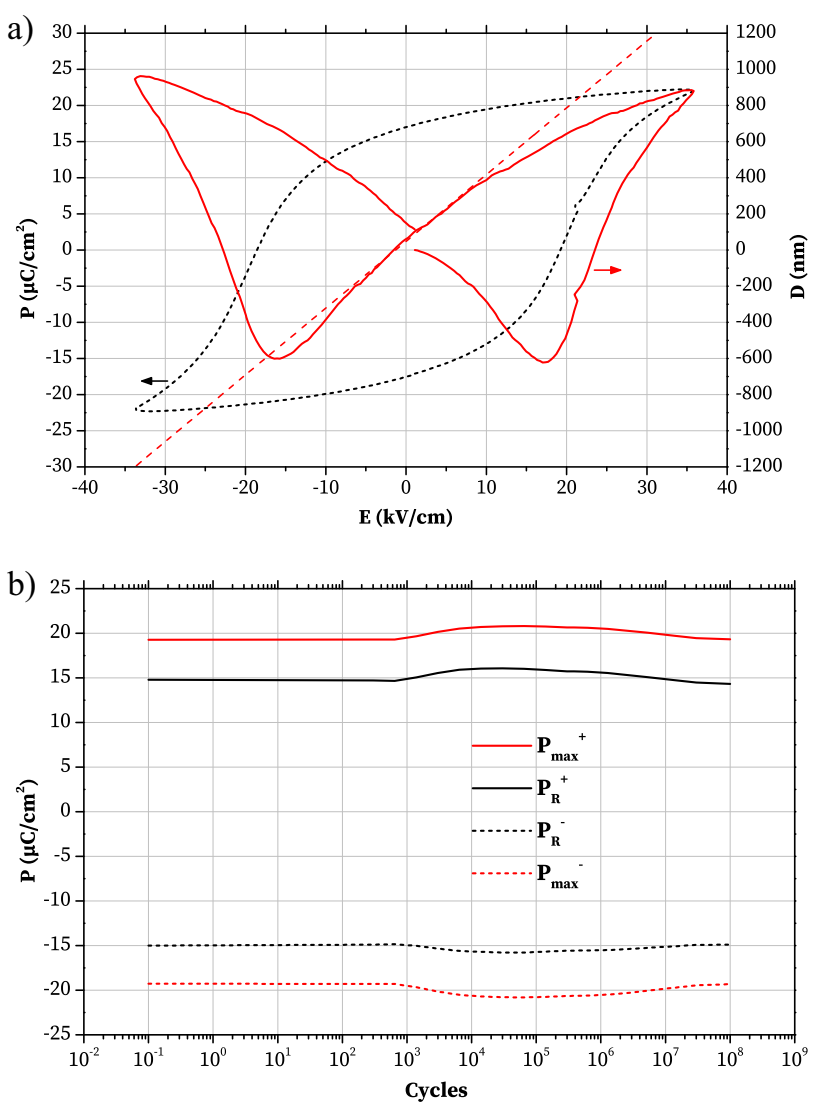

Fig. 6 a Polarization and strain loops of a $0.69 \mathrm{~mm}$ thick sol-gel derived PNZT pellet sintered at $1250{ }^{\circ} \mathrm{C}$. The slope of the dashed line is the longitudinal piezoelectric coefficient, $d_{33}=535(7) \mathrm{pm} / \mathrm{V}$. The slight asymmetry in the strain-field curve is likely due to residual stresses in the sample. b Fatigue response of the same pellet showing minimal degradation up to $10^{8}$ cycles

polarization measured for this pellet is $P_{\mathrm{r}}=17.0 \mu \mathrm{C} / \mathrm{cm}^{2}$, the coercive field $E_{\mathrm{c}}=19.1 \mathrm{kV} / \mathrm{cm}$, and the maximum longitudinal piezoelectric coefficient $d_{33}=535 \pm 7 \mathrm{pm} / \mathrm{V}$. The piezoelectric coefficient was obtained from the slope of the strain-field curve at zero field. The $d_{33}$ coefficient 
Table 1 Comparison of the longitudinal piezoelectric coefficient of the PNZT pellet fabricated using the ethylene glycol CSD method with literature values

\begin{tabular}{|c|c|c|c|}
\hline $\begin{array}{l}d_{33}(\mathrm{pm} / \mathrm{V}) \\
535(7)\end{array}$ & $\begin{array}{l}\text { Doping element } \\
\mathrm{Nb}\end{array}$ & $\begin{array}{l}\text { Method } \\
\text { CSD }\end{array}$ & $\begin{array}{l}\text { Reference } \\
\text { This work }\end{array}$ \\
\hline 500 & Commercial & n.a. & {$[27]$} \\
\hline 475 & Commercial & n.a. & [28] \\
\hline 420 & Undoped & Sol-gel & [29] \\
\hline 155 & Undoped & Wet chemical & {$[30]$} \\
\hline 300 & Undoped & Wet chemical & {$[31]$} \\
\hline 569 & $\mathrm{La}$ & Sol-gel & {$[32]$} \\
\hline 269 & $\mathrm{Nd}$ & Sol-gel & {$[32]$} \\
\hline 325 & $\mathrm{La}$ & Wet chemical & {$[33]$} \\
\hline 236 & $\mathrm{BiFeO}_{3} / \mathrm{CuO} / \mathrm{BaCu}_{0.5} \mathrm{~W}_{0.5} \mathrm{O}_{3}$ & Solid-state & {$[34]$} \\
\hline 338 & $\mathrm{La} / \mathrm{Nb}$ & Solid-state & {$[35]$} \\
\hline 520 & $\mathrm{Sr} / \mathrm{Nb}$ & Solid-state & {$[36]$} \\
\hline 255 & $\mathrm{Nb}$ & Solid-state & {$[37]$} \\
\hline
\end{tabular}

obtained here is compared to literature values in Table 1 . Our PNZT pellet has a piezoelectric coefficient comparable to the best materials found in literature, including commercially available piezoelectric elements. We expect that the ferroelectric and piezoelectric parameters can be further increased by bringing the composition closer to the MPB. Figure $6 \mathrm{~b}$ shows the fatigue response of the same sample. The polarization shows little to no degradation for at least $10^{8}$ cycles. This work shows that the ethylene glycol CSD method is capable of producing a high-quality material despite the simplicity of the method and the presence of a larger amount of organic material in the dried film.

\subsection{Thin films}

A nine-layer PNZT film was produced from the $1.5 \mathrm{M}$ PNZT sol by spinning at $5000 \mathrm{rpm}$ followed by drying on the hotplate, with pyrolysis and annealing steps performed after every third layer. During heat treatment of these films, lead can be lost through evaporation at the film surface and through diffusion into the silicon substrate. This leads to the formation of a layer of lead-deficient pyrochlore phase at the film surface or at the film-electrode interface. An excess of lead precursor can be added to the PNZT sol to compensate for this loss. However, too large an excess can cause the formation of voids in the film due to evaporation of the excess lead species. Therefore, careful control of the excess is required.

To achieve such control, an alternative method was used here. A relatively small excess of lead of $10 \%$ was added to the sol, aiming to compensate for diffusion but not for evaporation. In addition, a layer of pure $\mathrm{PbO}$ sol was deposited before the

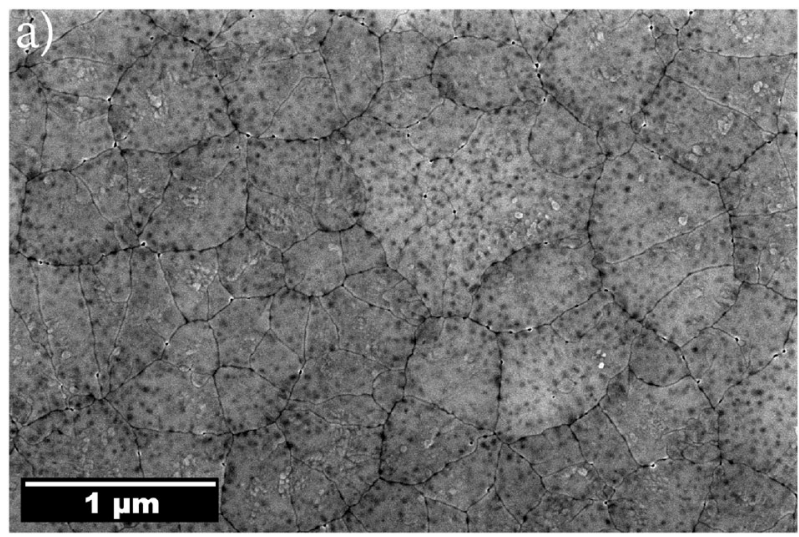

Fig. 7 Plan-view SEM image of a nine-layer PNZT thin-film stack with a $\mathrm{PbO}$ overcoat. The black spots visible on the film are due to pores present primarily at the surface

final pyrolysis step, compensating for evaporation from the film surface (see ref. [21]). The resulting film shows grains with sizes from several hundred nanometers up to $1 \mu \mathrm{m}$ (Fig. 7). Black spots on the surface of the film reveal the presence of voids, which are located mostly close to the surface. These voids are presumably caused by the presence of some residual organic material or a very slight excess of lead, but they do not penetrate through the film. Using this procedure, no leaddeficient pyrochlore phase was found and no cracks or leakage paths are visible. These observations show that the combination of a lead excess in the sol with a $\mathrm{PbO}$ overcoat is effective at producing crack-free thin films. A columnar grain structure is commonly observed in PZT thin films derived from traditional sol-gel methods based on 2-methoxyethanol, due to bottom-up growth of the grains after heterogeneous nucleation at the filmelectrode interface. Such structure is not present in these films, suggesting that the film nucleates more homogeneously throughout, as has been previously observed using diol-based sol-gel methods[18]. This may be the result of the high organic content of the as-deposited films compared to traditional sol-gel-derived films, the relatively high firing temperature and the high heating rate [18].

An X-ray diffraction pattern of the same film is shown in Fig. 8. The pattern shows a pure perovskite PNZT phase with no impurity peaks, except those originating from the platinized silicon substrate. No peak splitting is observed due to the broadening of the peaks. A small $\mathrm{Pt}(200)$ peak is present due to the top electrode, which is not perfectly (111) oriented. The preferential orientation of the PNZT film can be quantified by normalizing the integrated peak intensities with the intensities of the X-ray diffraction patterns of a powdered sample using the following expression [22]:

$P\left(h_{i} k_{i} l_{i}\right)=\frac{\frac{I\left(h_{i} k_{i} l_{i}\right)}{I^{*}\left(h_{i} k_{i} l_{i}\right)}}{\sum_{h k l} \frac{I(h k l)}{I^{*}(h k l)}}$ 


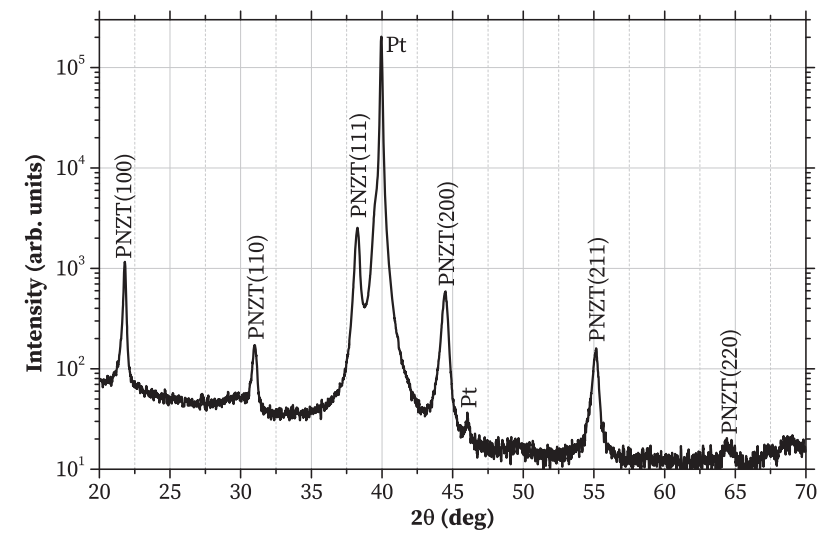

Fig. 8 XRD pattern of the nine-layer thin film stack

Table 2 Texture index values of the thin film sample

\begin{tabular}{ll}
\hline$<h_{i} k_{i} l_{i}>$ & $P\left(h_{i} k_{i} l_{i}\right)$ \\
\hline$<100>$ & 0.25 \\
$<110>$ & 0.0086 \\
$<111>$ & 0.59 \\
$<200>$ & 0.11 \\
$<211>$ & 0.020 \\
$<220>$ & 0.016 \\
\hline
\end{tabular}

where $P\left(h_{i} k_{i} l_{i}\right)$ is a texture index quantifying the preferred orientation of the sample, $I\left(h_{i} k_{i} l_{i}\right)$ is the intensity in the thin film sample and $I^{*}\left(h_{i} k_{i} l_{i}\right)$ is the intensity in the powdered sample. The values in Table 2 are obtained using the data in Fig. 8.

A $<111>$ orientation is preferred in these films due to the $<111>$ texture of the underlying platinum electrode, showing that at least some of the film nucleates heterogeneously at the film-electrode interface. However, it is evident that some of the film nucleates homogeneously, resulting in a decreased $<111>$ texture of the film. This is in agreement with the lack of bottom-up growth in the film.

Figure 9a shows the ferroelectric hysteresis loop and strain loop of a nine-layer PNZT thin film stack. A doublebeam laser interferometer [23], which corrects for substrate bending to extract the true deformation of the film, was used to collect these loops. The loops were collected by sweeping the potential applied to the top electrode between $+800 \mathrm{kV} / \mathrm{cm}$ and $-800 \mathrm{kV} / \mathrm{cm}$ using a triangular waveform at a frequency of $100 \mathrm{~Hz}$. The longitudinal piezoelectric coefficient is extracted from the strain loop by determining its slope at zero applied field. The film showed a remnant polarization of $10.5 \mu \mathrm{C} / \mathrm{cm}^{2}$, somewhat lower than values in literature $[17,18,24,25]$. The average coercive field was $61.3 \mathrm{kV} / \mathrm{cm}$, similar to the literature $[17,18,24]$. The longitudinal piezoelectric coefficient of $53 \pm 2 \mathrm{pm} / \mathrm{V}$ and a maximum deformation of $1.41 \mathrm{~nm}$, or $0.3 \%$ of the thickness
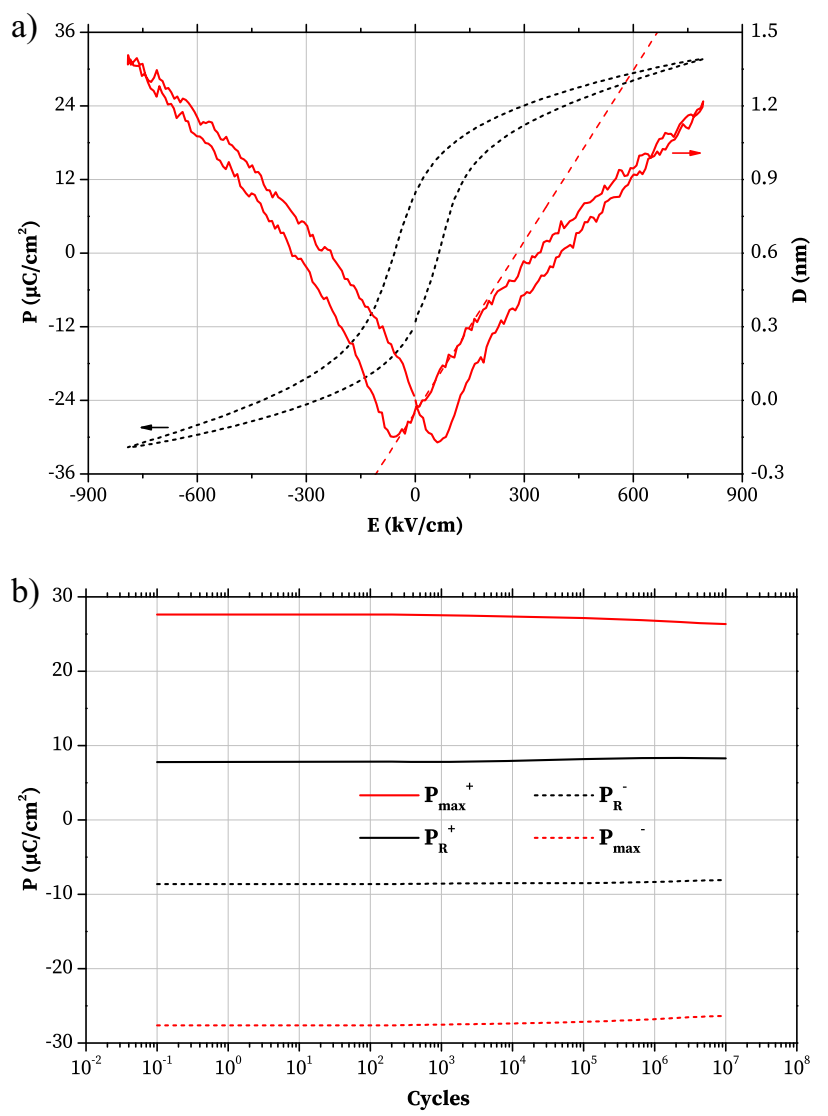

Fig. 9 a Ferroelectric and strain loop of the nine-layer PNZT thin film stack. The longitudinal piezoelectric coefficient is obtained from the slope of the strain loop at zero electric field, as indicated by the red tangent line. b Fatigue response of the film up to $10^{7}$ cycles

Table 3 Comparison of the longitudinal piezoelectric coefficient of the PNZT thin film fabricated using the ethylene glycol CSD method with literature values

\begin{tabular}{lll}
\hline$d_{33}(\mathrm{pm} / \mathrm{V})$ & Production method & $\begin{array}{l}\text { Reference } \\
50\end{array}$ \\
\hline 50 & CSD & This work \\
77 & Sol-gel & {$[22]$} \\
200 & Sol-gel & {$[38]$} \\
400 & OMCVD & {$[39]$} \\
85 & Sol-gel & {$[39]$} \\
$70-80$ & Sol-gel & {$[40]$} \\
200 & Sol-gel & {$[25]$} \\
25 & Sol-gel & {$[24]$} \\
57.6 & Sol-gel & {$[41]$} \\
$164 *$ & Sol-gel & {$[42]$} \\
106 & PLD & {$[43]$} \\
\hline
\end{tabular}

These results are for undoped PZT, unless otherwise noted $P L D$ pulsed laser deposition

*1\% $\mathrm{Nb}$ doping, OMCVD organometalic chemical vapor deposition 
of the film, are compared to literature values in Table 3, which displays the wide range of piezoelectric parameter values reported depending on the synthesis technique. Our piezoelectric coefficient is on the low end of this range, but improvements can likely be made. For example, fabrication of thicker films will improve piezoelectric behavior due to reduced clamping from the substrate. Furthermore, our film contains a large number of voids due to the relatively large organic content of the dried film compared to traditional methods. Increasing the density of the film by adjusting the heat treatment procedure will likely improve the piezoelectric coefficient as well.

Figure $9 \mathrm{~b}$ shows the fatigue response of the film. The film was switched at a frequency of $200 \mathrm{~Hz}$ with an electric field amplitude of $114 \mathrm{kV} / \mathrm{cm}$, that is above the coercive field. Ferroelectric hysteresis loops were collected at 3 points/decade with a field amplitude of $800 \mathrm{kV} / \mathrm{cm}$ and a frequency of $100 \mathrm{~Hz}$. The film is stable to fatigue for at least $10^{7}$ cycles. These results are similar to those reported in the literature (see, e.g., refs. [13, 22, 26]).

\section{Conclusion}

To summarize, a sol-gel method was developed based on ethylene glycol as a solvent and bridging ligand. This sol was used for the production of pellets and thin films of ferroelectric niobium-doped lead zirconate titanate. This sol offers the advantages of a lower toxicity solvent, improved stability during storage, decreased sensitivity to atmospheric moisture and the applicability to the synthesis of both bulk and thin-film products. Furthermore, the synthesis of the sol is less complex than that of traditional, 2-methoxyethanol-based sols. DTATGA of the sol shows that decomposition of the gel is finished at $600{ }^{\circ} \mathrm{C}$, with a total weight loss of $38 \%$. Pellets of bulk PNZT were produced, having a density of $99.3 \%$ of the theoretical density and small $\mathrm{PbO}$ and zirconia impurities. The pellets are in the tetragonal phase with a grain size of $1.21 \pm$ $0.54 \mu \mathrm{m}$. They show good properties with a coercive field of $19.1 \mathrm{kV} / \mathrm{cm}$, a remnant polarization of $17.0 \mu \mathrm{C} / \mathrm{cm}^{2}$ and a piezoelectric coefficient of $535 \pm 7 \mathrm{pm} / \mathrm{V}$, comparable to literature values for similar PZT compositions. The pellet shows resistance to fatigue up to at least $10^{8}$ cycles.

In addition, a nine-layer stack of PNZT thin films was fabricated from the sol by spin coating with a thickness of $440 \mathrm{~nm}$. An excess of lead was supplied to the thin films to compensate for evaporation and diffusion by combining the addition of an excess of lead precursor to the sol and the application of an overcoat of pure $\mathrm{PbO}$. This method proved effective at suppressing the presence of lead-deficient phases in the stack. The final stack shows a perovskite grain structure with a relatively large number of voids and a weak (111) out-of-plane texture. Ferroelectric and piezoelectric characterization of the film shows ferroelectric coefficients close to literature values for thin films, with a remnant polarization of $10.5 \mu \mathrm{C} / \mathrm{cm}^{2}$, a coercive field of $61.3 \mathrm{kV} / \mathrm{cm}$, a piezoelectric coefficient of $52 \pm 2 \mathrm{pm} / \mathrm{V}$ and a maximum deformation of $0.3 \%$ of the thickness of the film. Furthermore, the film shows good stability to fatigue up to $10^{7}$ cycles. This sol-gel method provides a safer, more water-stable alternative to traditional sol-gel methods based on 2-methoxyethanol for the fabrication of bulk and thin-film products.

Acknowledgements We gratefully acknowledge the invaluable help of Jacob Baas and Henk Bonder in the lab. We thank Miguel Badillo for fruitful discussions.

Author contributions EvdV and BN acknowledge financial support by the Ubbo Emmius Fonds of the University of Groningen. MA acknowledges financial support of a NWO-f Fellowship of the Dutch Research Council (NWO).

\section{Compliance with ethical standards}

Conflict of interests The authors declare no competing interests.

Publisher's note Springer Nature remains neutral with regard to jurisdictional claims in published maps and institutional affiliations.

Open Access This article is licensed under a Creative Commons Attribution 4.0 International License, which permits use, sharing, adaptation, distribution and reproduction in any medium or format, as long as you give appropriate credit to the original author(s) and the source, provide a link to the Creative Commons license, and indicate if changes were made. The images or other third party material in this article are included in the article's Creative Commons license, unless indicated otherwise in a credit line to the material. If material is not included in the article's Creative Commons license and your intended use is not permitted by statutory regulation or exceeds the permitted use, you will need to obtain permission directly from the copyright holder. To view a copy of this license, visit http://creativecommons. org/licenses/by/4.0/.

\section{References}

1. Hench LL, West JK (1990) Chem Rev 90:33-72

2. Schwartz RW, Schneller T, Waser R (2004) Comptes Rendus Chim 7:433-461

3. Livage J, Henry M, Sanchez C (1988) Prog Solid St Chem $18: 259-341$

4. Danks AE, Hall SR, Schnepp Z (2016) Mater Horizons 3:91-112

5. Yi GH, Sayer M (1991) Am Ceram Soc Bull 70:1173-1179

6. Bassiri-Gharb N, Bastani Y, Bernal A (2014) Chem Soc Rev 43:2125-2140

7. Budd KD, Dey SY, Payne DA (1985) Br Ceram Soc Proc 36:107-121

8. Kosec M, Malic B, Mandeljc M (2002) Mat Sci Semicon Proc 5:97-103

9. Muralt P (2000) J Micromech Microeng 10:136-146

10. Noheda B et al. (1999) Appl Phys Lett 74:2059-2061

11. Jaffe B, Cook WR, Jaffe HL (1971) Piezoelectric ceramics. Academic Press, Cambridge, Massachusetts, United States (Academic Press). 
12. Damjanovic D (1998) Rep Prog Phys 61:1267

13. Li Q et al. (2017) J Ceram Sci Technol 8:519-524

14. Niederberger M (2007) Acc Chem Res 40:793-800

15. De-Qing Z, Hong-Shan S, Shao-Jun W, Mao-Sheng C, Xui-Li W (2007) J Sol-Gel Sci Technol 41:157-161

16. Kingon AI, Clark BJ (1983) J Am Ceram Soc 66:253-256

17. Livage C, Safari A, Klein LC (1994) J Sol-Gel Sci Technol 2:605-609

18. Tu YL, Milne SJ (1995) J Mater Res 10:3222-3231

19. Noheda B, Gonzalo J, Cross L, Guo R (2000) Phys Rev B 61:8687-8695

20. Noheda B et al. (2000) Phys Rev B 63:014103

21. Brennecka GL, Ihlefeld JF, Maria JP, Tuttle BA, Clem PG (2010) J Am Ceram Soc 93:3935-3954

22. Balma D et al. (2014) J Am Ceram Soc 97:2069-2075

23. Pan WY, Cross LE (1989) Rev Sci Instrum 60:2701-2705

24. Chen HD et al. (1996) J Am Ceram Soc 79:2189-2192

25. Zavala G, Fendler JH, Trolier-McKinstry S (1997) J Appl Phys 81:7480-7491

26. Klissurska RD, Tagantsev AK, Brooks KG, Setter N (1997) J Am Ceram Soc 80:336-342

27. Hinterstein M et al. (2011) Phys Rev Lett 107:077602

28. Xu T-B et al. (2013) Smart Mater Struct 22:065015
29. Sharma PK, Ounaies Z, Varadan VV, Varadan VK (2001) Smart Mater Struct 10:878-883

30. Choy J-H, Han Y-S, Kim S-J (1997) J Mater Chem 7:1807-1813

31. Guiffard B, Troccaz M (1998) Mater Res Bull 33:1759-1768

32. Shannigrahi SR, Tay FEH, Yao K, Choudhary RNP (2004) J Eur Ceram 24:163-170

33. Sahoo B, Panda PK (2013) J Adv Ceram 2:37-41

34. Dong D, Murakami K, Kaneko S, Xiong M (1993) J Ceram Soc Jpn 101:1090-1094

35. Singh V, Kumar HH, Kharat DK, Hait S, Kulkarni MP (2006) Mater Lett 60:2964-2968

36. Zheng H, Reaney IM, Lee WE, Jones N, Thomas H (2001) J Eur Ceram 21:1371-1375

37. Garcia JE, Prez R, Albareda A, Eiras JA (2007) J Eur Ceram 27:4029-4032

38. Taylor D, Damjanovic D (2000) Appl Phys Lett 76:1615-1617

39. Lefki K, Dormans GJM (1994) J Appl Phys 76:1764-1767

40. Ledermann N et al. (2003) Sens Actuators A 105:162-170

41. Wang Y et al. (2002) Appl Phys Lett 80:97-99

42. Lian L, Sottos NR (2000) J Appl Phys 87:3941-3949

43. Nguyen MD et al. (2014) Ceram Int 40:1013-1018

44. Goh WC, Yao K, Ong CK (2005) Appl Phys A 81:1089-1093 